\title{
ENTRE A LEGALIDADE E A LEGITIMIDADE: OS DESAFIOS E AVANÇOS DO NEABI NA IMPLEMENTAÇÃO DA TEMÁTICA ÉTNICO-RACIAL NO CURRÍCULO
}

Márcia Moreira Custódio

Professora do Instituto Federal do Triângulo Mineiro - IFTM.

Líder do Grupo de Estudos e Pesquisas Quilombo Neabi - GEPQUIN/IFTM. Doutora em Letras/Estudos Literários pela Universidade Federal do Espírito Santo. E-mail: marciacustodio@iftm.edu.br

\section{Talita Lucas Belizário de Oliveira}

Servidora Técnica de Laboratório do Instituto Federal do Triângulo Mineiro - IFTM. Mestra em Geografia da Saúde pela Universidade Federal de Uberlândia - UFU. Vice-líder do Grupo de Estudos e Pesquisas Quilombo Neabi - GEPQUIN/IFTM.

E-mail: talita@iftm.edu.br

\begin{abstract}
RESUMO
Em virtude do reconhecimento da necessidade da inclusão da temática étnico-racial na educação, este artigo analisa se os objetivos propostos no Regulamento do Núcleo de Estudos Afro-Brasileiros e Indígenas do Instituto Federal do Triângulo Mineiro - NEABI/IFTM, no tocante à inserção da temática étnico-racial no currículo do IFTM, são alcançados por meio das ações desenvolvidas pelo NEABI. Para o encaminhamento da análise, o recurso metodológico empregado na pesquisa foi documental, sendo realizado estudo do Regulamento do NEABI/IFTM, bem como o mapeamento das ações do NEABI no contexto de 02 (dois) campi do IFTM, a fim de verificar se a atuação desses Núcleos atende ao exposto no documento que os rege. A partir de perspectivas teóricas que discutem a Rede Federal de Educação e currículo, concluiu-se que há necessidade de se estabelecer estratégias e planos visando à institucionalização efetiva do NEABI.
\end{abstract}

Palavras-chave: Educação. IFTM. Institucionalização.

\section{INTRODUÇÃO}

Já faz dezoito anos que foi sancionada a Lei $\mathrm{n}^{\circ} 10.639 / 2003$, cujo texto obriga a inclusão da temática "História e Cultura da Afro-Brasileira" no currículo da rede oficial de ensino. Tal medida trouxe mudanças na Lei de Diretrizes e Bases da Educação (LDB), em seus artigos 26 e 79. Em 2008, com a Lei n 11.645, a temática obrigatória do currículo é ampliada para a "História e Cultura Afro-Brasileira e Indígena".

Na perspectiva da educação, essas leis consistem em política de ação afirmativa pautada na demanda por reconhecimento, valorização e afirmação de direitos. Conforme aponta o parecer do Conselho Nacional de Educação/Conselho Pleno nº 003/2004 (CNE/CP 003/2004), "reconhecimento requer a adoção de políticas educacionais e de estratégias pedagógicas de valorização da diversidade, a fim de superar a desigualdade étnico-racial presente na educação escolar brasileira, nos diferentes níveis de ensino" (BRASIL, 2004, p. 3). 
Ora, com essas leis, a discussão da questão racial deixa de ser uma pauta restrita à luta dos movimentos negros, passando a ser uma questão política de Estado, pois torna-se responsabilidade das escolas, universidades, bem como dos agentes nelas envolvidos. Nesse sentido, fica evidente que "a luta pela superação do racismo e da discriminação racial é, pois, tarefa de todo e qualquer educador, independentemente do seu pertencimento étnico-racial, crença religiosa ou posição política" (BRASIL, 2004, p. 7).

Esse dispositivo legal de política curricular trata-se de uma ação afirmativa que visa a garantir reparações, reconhecimento e valorização de história, cultura, identidade dos povos negros e indígenas nas instituições de educação, implicando, dentre outras, estratégias pedagógicas de valorização da identidade e de garantia de acesso, permanência e êxito.

Nesse sentido, para a implementação das referidas leis, é necessária a construção de um currículo que contemple a inserção das diferentes identidades e diversidade cultural. No entanto, embora a escola se caracterize como um espaço multicultural, observam-se as relações hierárquicas da sociedade refletidas na estruturação de seu modelo organizacional, transferindo para o seu interior as desigualdades de uma sociedade discriminatória, que serão refletidas tanto nas relações interpessoais como na construção e transmissão do conhecimento, a saber, no currículo.

Nota-se essa contradição quando se verifica que, a despeito de haver legislação específica que obriga a abordagem da história e cultura africana e afro-brasileira e indígena no currículo, ainda é baixo o grau de institucionalização alcançado. Essa tarefa acaba se tornando complexa na medida em que exige mudanças estruturais que levem em conta não apenas as discriminações e as diferenças nas relações interpessoais, mas também a ressignificação de toda a ação escolar de forma a contemplar a multiculturalidade nos documentos institucionais, abarcando em sua política os grupos e culturas historicamente silenciados.

Nessa direção, para mediar o processo de implantação e implementação das políticas de ação afirmativa, os Núcleos de Estudos Afro-Brasileiros e Indígenas NEABIs - atuam nas instituições de ensino para o fortalecimento de uma educação antirracista, contribuindo para que essa discussão seja incorporada nas políticas institucionais. 
No sentido de perceber como acontece essa relação no IFTM, este trabalho se propõe a analisar se os objetivos propostos no Regulamento do NEABI/IFTM, no tocante à inserção da temática étnico-racial no currículo do IFTM, são alcançados por meio das ações desenvolvidas pelo NEABI. Com isso, além de se ampliar a discussão sobre a inserção da temática da História e Cultura Afro-Brasileira e Indígena no âmbito do currículo, pretende-se refletir sobre estratégias para implementação e cumprimento da legislação no âmbito do IFTM.

\section{MATERIAIS E MÉTODOS}

Por se configurar uma pesquisa básica, com foco na abordagem qualitativa e de natureza descritiva, o procedimento metodológico privilegia a análise documental. Com efeito, a "[...] pesquisa qualitativa preocupa-se [...] com aspectos da realidade que não podem ser quantificados, centrando-se na compreensão e explicação da dinâmica das relações sociais" (SILVEIRA; CÓRDOVA, p. 32).

Tal procedimento perpassa duas etapas: (1) a análise do Regulamento do NEABI/IFTM; (2) e o mapeamento das ações dos NEABIs de cada campus do IFTM. Com isso, pretende-se compreender em que medida a atuação do NEABI nos campi está em consonância com a proposta do Regulamento.

Por se tratar de uma pesquisa em sua fase inicial, desenvolvida pelo Grupo de Estudos e Pesquisas Quilombo Neabi (GEPQUIN) do IFTM, nesse primeiro momento, dentre os NEABIs dos 09 (nove) distribuídos no IFTM, apenas 02 (dois) participam dessa investigação, a saber, o NEABI-IFTM/campus Avançado Uberaba Parque Tecnológico e o NEABI-IFTM/campus Uberlândia.

\section{FUNDAMENTAÇÃO TEÓRICA}

A Lei $n^{\circ} 10.639 / 2003$ e a Lei $n^{\circ} 11.645 / 2008$ conferem à educação um caráter mais justo na compreensão de democratização da educação. Com efeito, quando se trata da Educação Básica Técnica e Tecnológica, por trazerem uma base educacional humanístico-técnico-científica, a introdução da temática étnico-racial nos currículos opera para reafirmar a formação humana e cidadã que se encontra no cerne dos seus princípios educativos. Segundo Pacheco (2020), os Institutos Federais têm como objetivo “[...] formar o cidadão capaz de compreender os processos produtivos e qual o 
seu papel nestes processos, incluindo as relações sociais estabelecidas a partir daí" (PACHECO, 2020, p. 11).

Portanto, vale ressaltar que as instituições que fazem parte da:

[...] Rede Federal de Educação Profissional, Científica e Tecnológica podem encontrar no ensino de história e cultura afro-brasileira e africana mais um elemento para a superação da dualidade entre formação humanística e formação profissional. Isso porque os cursos médios integrados aos cursos técnicos podem produzir uma integração fértil e inovadora dentro do universo representado pela ciência e a cultura (FONSECA; ROCHA, 2019, p. 4).

Portanto, tão providencial quanto necessária, a temática étnico-racial deve perpassar o currículo de todos os níveis e modalidades de ensino da Rede Federal de Educação Profissional, Científica e Tecnológica.

No entanto, esse processo, no contexto da educação profissional tecnológica, cujo foco, erroneamente interpretado, recai no mercado de trabalho, não acontece de forma tranquila, pelo contrário, sua abordagem vem sempre cercada de tensões. Em vista disso, Valentim (2011) afirma que "[...] esse professor expressa o modo de ver e de pensar predominante entre os professores das áreas técnicas. Ao declarar que as questões étnico-raciais não são temas do seu interesse, já que leciona disciplinas das áreas técnicas [...]” (VALENTIM, 2011, p. 6).

Constata-se, portanto, que, embora a introdução da temática étnico-racial se configure em demanda obrigatória, há resistência para sua inserção não só nos currículos como também no cotidiano da realidade das relações da educação dos Institutos Federais. Essa indiferença “[...] exige questionamento dos lugares de poder. Indaga a relação entre direitos e privilégios arraigada em nossa cultura política e educacional, em nossas escolas e na própria universidade" (GOMES, p. 100).

Segundo Silva (2011):

\begin{abstract}
As dificuldades para implantação dessas políticas curriculares, assim como a estabelecida no art. 26 da Lei $n^{\circ} 9.394 / 1996$, por força da Lei $n^{\circ} 10.639 / 2003$, devem-se muito mais à história das relações étnico-raciais neste país e aos processos educativos que elas desencadeiam, consolidando preconceitos e estereótipos, do que a procedimentos pedagógicos, ou à tão reclamada falta de textos e materiais didáticos (SILVA, 2011, p. 29).
\end{abstract}

Constituídas no âmbito de políticas públicas de promoção de igualdade como política de ação afirmativa ${ }^{1}$, a recusa pela implementação e cumprimento da Lei $\mathrm{n}^{\circ}$

\footnotetext{
${ }^{1}$ Segundo Silvio de Almeida (2019, p. 145), “as ações afirmativas são políticas públicas de promoção de igualdade nos setores público e privado, e que visam a beneficiar minorias sociais historicamente 
10.639/2003 e da Lei $n^{\circ} 11.645 / 2008$ ou a falta de reconhecimento desses preceitos legais no âmbito da educação só pode ser compreendida como racismo institucional. No que tange à abordagem da temática étnico-racial na escola, há uma relação descontínua, conflituosa e tensa, que se materializa por meio da inação, muitas vezes intencional.

De acordo com Gomes (2012):

[...] a discriminação racial se faz presente como fator de seletividade na instituição escolar e o silêncio é um dos rituais pedagógicos por meio do qual ela se expressa. Não se pode confundir esse silêncio com o desconhecimento sobre o assunto ou a sua invisibilidade. É preciso colocá-lo no contexto do racismo ambíguo brasileiro e do mito da democracia racial e sua expressão na realidade social e escolar. O silêncio diz de algo que se sabe, mas não se quer falar ou é impedido de falar. No que se refere à questão racial, há que se perguntar: por que não se fala? Em que paradigmas curriculares a escola brasileira se pauta a ponto de "não poder falar" sobre a questão racial? E quando se fala? O que, como e quando se fala? O que se omite ao falar? (GOMES, 2012, p. 105).

Nesta medida e nos termos, é urgente que a escola proponha políticas de enfrentamento ao racismo, de modo que a legislação seja legitimada no seu interior. É preciso que as instituições escolares, em seus Planos de Desenvolvimento Institucional, tenham como perspectiva a inclusão da diversidade em todos os âmbitos, indo desde a inserção da temática étnico-racial no currículo à capacitação de servidores para atuar com essa abordagem, visando a corrigir as falhas históricas de omissão, silenciamento, desvalorização das contribuições, intervenções e resistências de nossas matrizes indígenas e africanas.

\section{OS NÚCLEOS DE ESTUDOS AFRO-BRASILEIROS E INDÍGENAS}

Há cerca de 60 anos, o Centro de Estudos Afro-Orientais (CEAO) (TELES, 2004) da Universidade Federal da Bahia (UFBA) iniciava pesquisas sobre as comunidades negras no Brasil, assim como suas origens na África, influenciando na formação dos primeiros grupos, núcleos, laboratórios ou centros de estudos e pesquisas voltados para as questões afro-brasileiras em outras instituições de ensino superior públicas e privadas. Todavia, na perspectiva de políticas públicas educacionais voltadas para as relações étnico-raciais, essa luta ganha força no início dos anos 1970, com a consolidação do Movimento Negro Unificado (MNU), pois, com o advento e a "[...] difusão de sua proposta política, objetivada em seu Programa de Ação e em sua Carta de

discriminadas. Tais políticas podem realizadas das mais diversas modalidades e ser aplicadas em inúmeras áreas". 
Princípios, inspirou a criação de diversas entidades e grupos negros em vários pontos do país" (GONZALEZ, 1982, p. 64-65).

Segundo Oliveira; Costa (2019):

Os Núcleos de Estudos Afro-Brasileiros (NEABs) e os diferentes grupos correlatos espalhados em várias instituições de ensino no país, derivam do processo de democratização do Estado, criado a partir do contexto de luta e reivindicações do Movimento Negro diante da necessidade do aprofundamento do debate sobre as questões raciais e da importância de ampliação dos espaços políticos, institucionais e acadêmicos para negros(as) descendentes de africanos escravizados no Brasil (OLIVEIRA; COSTA, 2019, p. 1-2).

Nessa perspectiva, Gomes (2011) afirma que:

[...] o movimento negro, no Brasil, conquanto sujeito político, tem sido o principal responsável pelo reconhecimento do direito à educação para a população negra, pelos questionamentos ao currículo escolar no que se refere ao material didático que apresenta imagens estereotipadas sobre o negro, pela inclusão da temática racial na formação de professores(as), pela atual inclusão da história da África e da cultura afro-brasileira nos currículos escolares e pelas políticas de ação afirmativa nas suas mais diferentes modalidades (GOMES, 2011, p. 137).

Ora, o diálogo entre professores militantes e intelectuais do Movimento Negro ${ }^{2}$ nas universidades culmina com a realização do I Congresso Brasileiro de Pesquisadores/as Negros/as (COPENE), na cidade Recife-PE, e na criação da Associação Brasileira de Pesquisadores/as Negros/as (ABPN). Tal movimento leva à criação dos Núcleos de Estudos Afro-Brasileiros (NEABs) nas instituições de ensino superior. Sancionada a Lei 10.639/2003, ratifica-se a importância dos NEABs na implantação e fortalecimento de ações afirmativas nas instituições de ensino.

Destacando o caráter estratégico dos NEABs, Ferreira; Coelho (2019) pontuam que:

[...] os NEABs em parceria com o Ministério da Educação (MEC), Secretaria de Educação Continuada, Alfabetização, Diversidade e Inclusão (SECADI), Secretaria de Políticas de Promoção da Igualdade Racial (SEPPIR) e Comissão Técnica Nacional de Diversidade para assuntos relacionados à Educação dos Afro-brasileiros (CADARA) constituíram-se no decorrer dos anos, pós-aprovação da Lei n.10.639/2003, como órgãos partícipes nos processos de formulação, implantação e implementação de ações de promoção da igualdade racial (FERREIRA;COELHO, 2019, p. 219-220).

2 Conforme explicita Lélia Gonzalez (1982, p. 42), as bases do Movimento Negro Unificado Contra a Discriminação Racial foram lançadas em 1978. 
Entende-se, portanto, que a Lei $n^{\circ} 10.639 / 2003$ coloca os NEABs como elemento dinamizador do processo de institucionalização da educação das relações raciais nas instituições, uma vez que:

[...] ganham cada vez mais importância e significado como espaços de formação política com caráter pedagógico e de produção do conhecimento contra hegemônico. Ao combater o racismo do ponto de vista epistemológico, esses Núcleos, ao mesmo tempo, combatem o racismo institucional atuando de forma efetiva nas diferentes instâncias e órgãos que compõem a estrutura universitária e as relações de poder institucionalizado (OLIVEIRA; COSTA, 2019, p. 4-5).

Se em seu início os NEABs visavam à consolidação de direitos estabelecidos por políticas públicas no âmbito da Lei Federal $n^{\circ} 10.639 / 2003$, mais à frente, com aprovação da Lei $\mathrm{n}^{\mathrm{o}} 11.645 / 2008$, terão suas ações expandidas para os estudos e pesquisas da história e cultura indígenas, passando então a se denominar NEABI Núcleo de Estudos Afro-Brasileiros e Indígenas.

Consoante com o "Plano Nacional de Implementação das Diretrizes Curriculares Nacionais para a Educação das Relações Étnico-raciais e para o Ensino de História e Cultura Afro-brasileira e Africana" (BRASIL, 2009, p. 46), documento que aponta as ações da competência dos NEABs e Grupos Correlatos como o NEABI, dentre outras ações, devem ser realizadas por esses Núcleos a formação continuada dos professores e estudantes, a elaboração de material didático específico, a mobilização de recursos para a implementação da temática e a divulgação e disponibilização de estudos e pesquisas materiais didáticos e atividades de formação continuada.

\section{RESULTADOS E DISCUSSÕES}

Podemos compreender que a implementação da educação das relações étnicoraciais nas escolas que compõem a Rede Federal de Educação Profissional, Científica e Tecnológica começa a ganhar fôlego com a implantação dos NEABIs nas instituições.

A respeito do NEABI no Instituto Federal de Educação, Ciência e Tecnologia do Triângulo Mineiro - IFTM, sua presença remonta ao início do funcionamento dessa instituição. Criado em 29 de dezembro de 2008, pela Lei ${ }^{\circ} 11.892$, o IFTM é uma Instituição de Educação Superior, Básica e Profissional, pluricurricular e multicampi. Atuando em diferentes níveis e modalidades de ensino, o IFTM atualmente é composto por nove campi. Vinculado à Pró-Reitoria de Ensino, o NEABI foi implantado no IFTM 
em 2012, pela Resolução n ${ }^{\circ}$ 43/2012, de 26 de novembro de 2012, com a finalidade de implementar a Lei $\mathrm{n}^{\mathrm{o}} 11.645 / 2008$.

Em 2020, por meio da Resolução “Ad Referendum” no 010/2020, de 22 de junho de 2020, a colaboração dos NEABIs de cada campus do IFTM, com ações que vão desde a capacitação à indicação de membros para a Comissão Recursal e Comissões Locais de procedimentos de verificação da Auto declaração de candidatos autoidentificados como negros (pretos ou pardos) e indígenas - PPI, nos processos seletivos para ingresso de discentes em vagas iniciais dos cursos técnicos, de graduação e de pós-graduação.

Atualmente, todos os campi contam com um NEABI local, composto por representação de, no mínimo, 01 docente, 01 técnico administrativo, 01 estudante do nível médio técnico, 01 estudante do nível superior e 02 membros da comunidade externa. Todos esses representantes são indicados pela direção geral de cada campus. No entanto, não havendo um NEABI central, a articulação das ações fica restrita a iniciativas isoladas dos membros de cada Núcleo local, voltadas geralmente para o respectivo campus.

No Plano de Desenvolvimento Institucional 2019-2023 (IFTM, 2019), a respeito da inserção da temática étnico-racial no currículo, o documento traz:

[...] as iniciativas de inserção de disciplinas relativas à Educação das Relações Étnico-raciais no currículo dos cursos está entre as premissas da organização dos Projetos Pedagógicos dos Cursos, respeitada a autonomia de construção, naquilo que é pertinente, seguindo a obrigatoriedade, nestas questões, prevista pela Lei no 11.645/2008 (IFTM, 2019, p. 118).

Em seguida, o texto explicita que é responsabilidade do NEABI "[...] acompanhar, no que lhe couber, as ações de implementação da referida Lei” (IFTM, 2019, p. 118). Em consonância com o referido texto do PDI, o artigo $3^{\circ}$ do Regimento do NEABI/IFM aponta doze objetivos:

I. Divulgar a influência e a importância da cultura negra, afrodescendente e indígena na formação do povo brasileiro e suas repercussões no âmbito do país, do estado, da região e do município;

II. Promover a realização de atividades de extensão como cursos, seminários, palestras, conferências e atividades artístico-culturais voltadas para a formação inicial e continuada referentes às temáticas de que tratam o presente regulamento;

III. Organizar encontros de reflexão e capacitação de servidores em educação para o conhecimento e a valorização da história dos povos africanos, da cultura afro-brasileira e indígena e da diversidade na construção histórica e cultural do país; 
IV. Implementar ações inerentes à Lei 11.645/08 direcionadas para uma educação pluricultural, para a construção da cidadania por meio da valorização da identidade étnico-racial, principalmente de negros, afrodescendentes e indígenas;

V. Fazer intercâmbio entre os câmpus do IFTM e escolas da rede pública (estadual e municipal) e privada, comunidades negras rurais, quilombolas, aldeias e outras instituições públicas e privadas com o intuito de realização de atividades voltadas para as questões étnico-raciais dos negros, afrodescendentes e indígenas;

VI. Promover a realização de pesquisas e a publicação de resultados relacionados à questão do negro, afrodescendente e indígena em variados veículos de comunicação;

VII. Propor ações que levem a conhecer o perfil da comunidade interna e externa nos aspectos étnico-raciais;

VIII. Estimular o desenvolvimento de conteúdos curriculares e pesquisas com abordagens multi, trans e interdisciplinares, de forma contínua e permanente; IX. Realizar discussões sobre os componentes curriculares dos cursos ofertados pelo IFTM no sentido de concretizar o Plano Nacional de Implementação da Lei 11.645/2008;

X. Articular ações entre ensino, pesquisa e extensão, de caráter interdisciplinar, que permitam desenvolver a temática da diversidade étnicoracial;

XI. Assessorar o trabalho docente na busca de temáticas étnico-raciais, metodologias de ensino/ aprendizagem e propostas de atividades de avaliação no desenvolvimento das ações relacionadas aos negros, afrodescendentes e indígenas;

XII. Criar estratégias de divulgação do conjunto de ações, estudos, conteúdos (textos, artigos, monografias, dissertações, teses e vídeos) e propostas do Núcleo como suporte para o trabalho docente, sobretudo por meio do portal da web, relacionadas especificamente ao estudo das questões étnico-raciais dos negros, afrodescendentes e indígenas.

Tomando os objetivos como indicadores, será feita a análise das ações realizadas pelos NEABIs do IFTM/campus Uberlândia e do IFTM/campus Avançado Uberaba Parque Tecnológico. Nos dois campi é possível notar um período de inatividade do NEABI local. O campus Uberlândia, antiga Escola Agrotécnica, passou a integrar a política de Educação profissional e tecnológica brasileira com a criação da rede dos Institutos Federais a partir da Lei n ${ }^{\circ}$ 11.892/2008. Contudo, embora a implantação do NEABI esteja formalizada desde 2012, as atividades do referido Núcleo terão início somente a partir de 2019:

Tabela 1 - Ações do NEABI do IFTM/campus Uberlândia

\begin{tabular}{cccc}
\hline Objetivos & Ações 2019 & Ações 2020 & Aç̃̃es 2021 \\
\hline I & - & 01 & - \\
II & 01 & 02 & 01 \\
III & - & 01 & 01 \\
IV & - & 01 & - \\
V & - & - & - \\
VI & - & - & 02 \\
VII & - & - & -
\end{tabular}




\section{Pcovisto

Para explicitar as ações da Tabela 1, segue abaixo resumo de algumas atividades e projetos desenvolvidos pelo NEABI/campus Uberlândia:

Objetivo I: Produção de vídeo institucional do NEABI/campus Uberlândia (2020).

Objetivo II: Produção de vídeo para o "Dia da Abolição" (2019); Organização do "Concurso de fotografia do NEABI" (2020); Realização dos eventos: "I Seminário Indígena e Afro-Brasileiro (SEMINAFRO)", promovido em parceria com as PróReitorias de Ensino e Extensão do IFTM (2020); "II Semana dElas e I Acolhimento NEABI", em parceria com o GEPQUIN e NEABI/campus Avançado Uberaba Parque Tecnológico (2021).

Objetivo III: Organização de cursos de capacitação para servidores do IFTM (2020); Projeto de extensão multicampi: "Escurecendo o pensamento", em parceria com o GPQUIN e NEABI/campus Avançado Uberaba Parque Tecnológico (2021).

Objetivo IV: Participação na revisão do regulamento disciplinar do corpo discente do IFTM/campus Uberlândia (2020).

Objetivo VI: Projeto de pesquisa "As Leis 10.639 e 11.645 no currículo do IFTM/campus Uberlândia" (2021); Projeto de pesquisa "Estudo da evasão e êxito dos alunos cotistas negros matriculados no IFTM/campus Uberlândia” (2021).

Pela análise da Tabela 01, depreende-se que a ênfase das ações do NEABIIFTM/campus Uberlândia recaiu na realização de eventos e em intercâmbio com outras instituições públicas - compreendido como objetivo II do Regulamento do NEABI/IFTM.

$\mathrm{Na}$ sequência, seguimos para a análise das ações do IFTM/campus Uberaba Parque Tecnológico. Fundada em 30 de setembro de 2014, pela portaria 188/2014, teve seu funcionamento aprovado em 21 de janeiro de 2015 pela portaria 89/2015, já com o NEABI presente em seu primeiro Regulamento. Contudo, o Núcleo se tornará operante só a partir de 2018, quando é emitida a primeira portaria listando seus membros. O 
quadro a seguir apresenta o volume de ações por período, tomando como indicadores os objetivos constantes no regimento do NEABI/IFTM:

Tabela 2 - Ações do NEABI-IFTM/campus Avançado Uberaba Parque Tecnológico

\begin{tabular}{ccccc}
\hline Objetivos & Ações 2018 & Ações 2019 & Ações 2020 & Ações 2021 \\
\hline I & - & - & - & - \\
II & 02 & 04 & 05 & 01 \\
III & - & - & 01 & - \\
IV & 01 & - & - & - \\
V & 01 & 02 & 06 & - \\
VI & - & 01 & 01 & - \\
VII & - & - & - & - \\
VIII & - & - & - & - \\
IX & - & - & - & - \\
X & - & - & - & - \\
XI & - & - & - & - \\
XII & - & - & - & - \\
\hline
\end{tabular}

Fonte: Elaborada pelas autoras

Para efeito de conhecimento e conferência, segue resumo das atividades e projetos desenvolvidos pelo NEABI-IFTM/campus Avançado Uberaba Parque Tecnológico lançados na Tabela 2:

Objetivo II: Oficina de confecção e exposição de máscaras africanas com estudantes e servidores (2018); Criação de uma logo para a identidade do Núcleo (2018); Realização de uma oficina de Slam Poetry (2019); Organização de um campeonato de Slam Poetry (2019); Produção de vídeo em homenagem ao "Dia do Índio" (2020); Realização dos seguintes eventos: "Raízes Indígenas” (2019); "Semana da Consciência Negra: A coisa tá preta no IFTM" (2019); "I Semana dElas: conversando sobre gênero, raça e tecnologia" (2020); "I Seminário Desmistificando a abolição" (2020); “A gosto do negro: as relações étnico-raciais em projeção" (2020); "I Seminário Indígena e Afro-Brasileiro (SEMINAFRO)", promovido pelas Pró-Reitorias de Ensino e Extensão do IFTM (2020); “II Semana dElas e Acolhimento Neabi”, em parceria com o GPQUIN e NEABI-IFTM/campus Avançado Uberaba Parque Tecnológico (2021).

Objetivo III: Curso de capacitação para servidores do IFTM, em parceria com o NEABI-IFTM/campus Uberlândia (2020).

Objetivo IV: Criação do Centro de Custos do NEABI (2018).

Objetivo V: Participação dos membros na "Semana da Consciência e Inclusão", evento realizado pelo campus Uberaba (2018); Realização da visita técnica “Troca de 
Saberes", na qual o NEABI organizou a ida de estudantes do ensino técnico integrado a uma aldeia indígena Javaé, no Tocantins (2019); Visita técnica com apresentação de trabalhos no II Arte\&Manha do IFTO/campus Gurupi (2019); Palestras da presidenta do NEABI nos seguintes eventos: "8 de março: mulheres e luta", promovido pelo campus Uberaba (2020); Roda de Conversa "Vidas Pretas Importam", organizado pela Próreitoria de Ensino (2020); "I SEMINAFRO”, produzido pela Pró-Reitoria de Ensino e Extensão do IFTM (2020); “III Arte \& Manha”, do IFTO/campus Gurupi (2020); "5 Afro com Ciência”, do IFTO/campus Dianópolis (2020); “Afropresença no Brasil”", promovido pelo NEABI/IFNMG-campus Pirapora (2020).

Objetivo VI: Criação do Grupo de Estudos e Pesquisa Quilombo NEABI (GEPQUIN) em 2019; Apresentação de trabalho na X Semana de Iniciação Científica e Inovação (SIN), que consiste num evento realizado pelo Pró-reitoria de Pesquisa do IFTM (2020).

Pela análise da Tabela 02, depreende-se que a ênfase das ações do NEABIIFTM/campus Avançado Uberaba Parque Tecnológico recaiu na realização de eventos de extensão e em intercâmbio com outras instituições públicas, que são os objetivos II e $\mathrm{V}$ do regimento do NEABI/IFTM.

É fato que a criação dos NEABIs nos referidos campi deu início ao desenvolvimento das ações para promoção da diversidade e do combate à desigualdade racial no âmbito do IFTM. Não obstante aos avanços que tal iniciativa represente à abrangência da referida abordagem, pela ausência de importantes objetivos que deveriam ser alcançados, o resultado das ações dos referidos Núcleos demonstra que os esforços engendrados ficam a nível local, sem uma abrangência maior, devido à falta de uma articulação central.

Com efeito, o cumprimento de todos os objetivos presentes no Regulamento é uma tarefa muito difícil de ser realizada pelo NEABI a nível local. A curricularização da temática étnico-racial, por envolver projeto político pedagógico, formação de professores, introdução de componente curricular na licenciatura entre outras, demanda uma articulação de um NEABI central, que faça intermediação com as pró-reitorias para a construção de estratégias para o cumprimento da Lei no $10.645 / 2008$. Ademais, para que os objetivos do Regulamento do NEABI/IFTM sejam alcançados, é preciso direcionar editais específicos de projetos de ensino, pesquisa e extensão voltados para a diversidade. No lugar de ações isoladas, é preciso que, a partir de um núcleo central, 
construam-se planos e metas comuns para os NEABIs locais, de modo que haja uma ação conjunta, articulada com a comunidade, pois não se trata apenas de mencionar a temática étnico-racial - o que ocorre quando se foca em eventos pontuais -, mas, sim, de torná-la ação efetiva no cotidiano do IFTM e seu entorno.

Vale lembrar que o Plano Nacional de Educação (Lei nº 13.005/2014) prevê na Estratégia 7.25 da meta 7 a garantia nos currículos escolares dos conteúdos sobre a história e as culturas afro-brasileira e indígenas bem como a implementação de ações educacionais nos termos das leis 10.639/03 e 11.645/08. Já na Estratégia 6.26 da mesa 7, prevê a oferta de programa de formação inicial e continuada de profissionais da educação.

\section{CONSIDERAÇÕES FINAIS}

A título de considerações, mas sem a pretensão de esgotar o tema, eis alguns apontamentos. Antes de qualquer coisa, gostaríamos de retomar a centralidade da temática de curricularização da temática étnico-racial em um cenário em que a demanda por uma educação antirracista é crescente. Dessa forma, é inevitável não discutir o cumprimento da Lei 11.645/2008, que é a obrigatoriedade da implementação da temática "História e Cultura Afro-Brasileira e Indígena" no currículo. No entanto, com ações isoladas, o NEABI não terá sucesso enquanto mediador desse processo.

De maneira sintética, podemos dizer que a inserção da temática étnico-racial no currículo perpassa pelas seguintes etapas: Institucionalizar as Leis 10.639/03 e 11.645/08 e diretrizes curriculares nacionais nas ações de ensino/pesquisa e extensão e políticas de formação de servidores e da comunidade; Atualizar regimento e/ou criar nos documentos institucionais (PDI/PPI e PPC) as alterações que se fizerem necessárias para educação das relações étnico-raciais; Ofertar formação na temática Étnico-racial para todos os servidores e terceirizados. Promover, de forma colaborativa, nos campi do IFTM, a gestão e produção de material didático para atendimento das leis $\mathrm{n}^{\circ}$. 10.639/2003 e 11.645/2008; Ter a garantia de dotação orçamentária para tais fins; Ter a presença de um NEABI central representando os órgãos colegiados locais.

A análise do Regimento do NEABI/IFTM e das ações dos NEABIs nos campi demonstra que entre a legalidade e a legitimidade das leis 10.639/2003 e 11.645/2008 ainda há um longo caminho a percorrer. 


\section{REFERÊNCIAS}

BRASIL. Constituição (1988). Constituição da República Federativa do Brasil. Brasília, DF: Centro Gráfico, 1988.

BRASIL. Lei $n^{\circ} 10.639$, de 9 de janeiro de 2003. Altera a Lei $n^{0} 9.394$, de 20 de dezembro de 1996, que estabelece as diretrizes e bases da educação nacional, para incluir no currículo oficial da Rede de Ensino a obrigatoriedade da temática "História e Cultura Afro-Brasileira", e dá outras providências. Diário Oficial da União, Brasília, DF, 10 jan. 2003, p. 1.

BRASIL. Ministério da Educação. Conselho Nacional da Educação. Conselho Pleno. Parecer $n^{\circ}$ 003/2004. Institui Diretrizes Curriculares Nacionais para a Educação das Relações Étnico-Raciais e para o Ensino de História e Cultura Afro-Brasileira e Africana. Diário Oficial da União, Brasília, DF, 19 mai. 2004. Seção 1, p. 19. Resolução CNE/CP 1/2004, publicada no DOU 22 jun. 2004, Seção 1, p. 11.

BRASIL. Lei $\mathrm{n}^{\circ} 11.645$, de 10 de março de 2008. Altera a Lei $\mathrm{n}^{\circ}$ 9.394, de 20 de dezembro de 1996, modificada pela Lei $\mathrm{n}^{\circ} 10.639$, de 9 de janeiro de 2003, que estabelece as diretrizes e bases da educação nacional, para incluir no currículo oficial da rede de ensino a obrigatoriedade da temática "História e Cultura Afro-Brasileira e Indígena". Diário Oficial da União, Brasília, DF, 11 mar. 2008, p. 1.

BRASIL. Lei $n^{\circ} 11.892$, de 29 de dezembro de 2008. Institui a Rede Federal de Educação Profissional, Científica e Tecnológica, cria os Institutos Federais de Educação, Ciência e Tecnologia, e dá outras providências. Diário Oficial da União, Brasília, DF, 30 dez. 2008a, p. 1.

BRASIL. Plano Nacional de Implementação das Diretrizes Curriculares Nacionais para a Educação das Relações Étnico-raciais e para o Ensino de História e Cultura Afro-Brasileira e Africana. Brasília: SECAD; SEPPIR, jun. 2009.

BRASIL. Lei no 13.005 , de 25 de junho de 2014. Aprova o Plano Nacional de Educação - PNE e dá outras providências. Diário Oficial da União, Brasília, DF, 26 jun. 2014, Edição extra.

FERREIRA, Anne de Matos Souza; COELHO, Wilma de Nazaré Baía. Ações dos Núcleos de Estudos Afro-Brasileiros (NEABs) institucionalizados dos Institutos Federais de Educação, Ciência e Tecnologia (IFETs) no período de 2006 a 2017. In: Revista Exitus, [S. l.], v. 9, n. 5, p. 215-242, 2019.

FONSECA, Marcus Vinícius; ROCHA, Laura Fernanda Rodrigues da. O processo de institucionalização da Lei $n^{\circ}$. 10.639/2003 na Rede Federal de Educação Profissional, Científica e Tecnológica. In: Educação Revista, Belo Horizonte, v. 35, e187074, 2019.

GOMES, Nilma Lino. O movimento negro no Brasil: ausências, emergências e a produção de saberes. In: Política \& Sociedade, v. 10, n. 18, p. 133-154, 2011. 
GOMES, Nilma Lino. Relações étnico-raciais, educação e descolonização dos currículos. In: Currículo sem Fronteiras, v.12, n.1, pp. 98-109, jan./abr. 2012, p. 98109).

GONZALEZ, Lelia; HASENBALG, Carlos. Lugar de negro. Rio de Janeiro: Marco Zero, 1982.

INSTITUTO FEDERAL DO TRIÂNGULO MINEIRO - IFTM. Plano de Desenvolvimento Institucional 2019-2023. Uberaba, 2019. Disponível em: <https://iftm.edu.br/pdi/acompanhamento/2019-2023.pdf>. Acesso em: 23 abr. 2021.

INSTITUTO FEDERAL DO TRIÂNGULO MINEIRO - IFTM. Resolução no 43, de 26 de novembro de 2012. Dispõe sobre a regulamentação do Núcleo de Estudos AfroBrasileiros e Indígenas do Instituto Federal de Educação, Ciência e Tecnologia do Triângulo Mineiro (NEABI/IFTM). Uberaba: Conselho Superior do IFTM, 26 nov. 2012.

INSTITUTO FEDERAL DO TRIÂNGULO MINEIRO - IFTM. Resolução "Ad Referendum" n" 010, de 22 de junho de 2020. Dispõe sobre os procedimentos de verificação da autodeclaração de candidatos autoidentificados negros (pretos e pardos) e indígenas para ingresso em vagas iniciais dos cursos técnicos, de graduação e pósgraduação do IFTM. Uberaba: Conselho Superior do IFTM, 22 jun. 2020.

OLIVEIRA, O. F. de; COSTA, R. D. da. Produção de conhecimentos, formação política e enfrentamento ao racismo na educação brasileira (Dossiê LEAFRO 10 anos). In: Repecult - Revista Ensaios e Pesquisa em Educação e Cultura - II Dossiê, v. 4, n. 6, p. 1-14, 2019.

PACHECO, Eliezer. Desvendando os Institutos Federais: Identidades e objetivos. In: Educação Profissional e Tecnológica em Revista, v. 4, n 1, p. 4-22, 2020.

SILVA, Petronilha Beatriz Gonçalves e. Aprender, ensinar e relações étnico-raciais no Brasil. In: FONSECA et al. (Org.). Relações étnico-raciais e educação no Brasil. Belo Horizonte: Mazza Edições, 2011.

SILVEIRA, Denise Tolfo; CÓRDOVA, Fernanda Peixoto. A pesquisa científica. In: GERHARDT, T. E.; SILVEIRA, D. T. (Org.). Métodos de pesquisa. Porto Alegre: Editora da UFRGS, 2009. p. 31-42.

TELES, Jocélio. Um centro dedicado à pesquisa dos negros. In: Estudos Avançados, São Paulo, v. 18, n. 50, pág. 141-145, abril de 2004.

VALENTIM, Silvani dos Santos. Questões étnico-raciais e a prática pedagógica dos professores do Curso Técnico em Mecânica do CEFET-MG. In: Revista Thema, v. 8, número Especial, 2011.

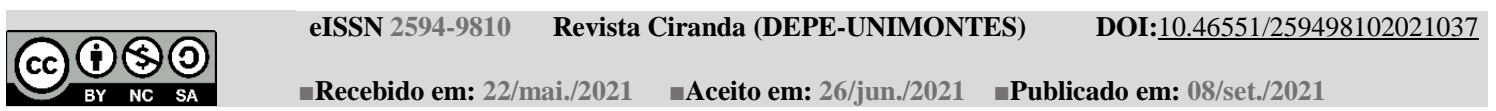

